\title{
EVOLUTION OF PROJECT-BASED LEARNING IN SMALL GROUPS IN ENVIRONMENTAL ENGINEERING COURSES
}

\author{
Jesús M. Requies $^{1} \mathbb{D}$, Ion Agirre ${ }^{* 1} \mathbb{D}$, V. Laura Barrio ${ }^{1} \mathbb{D}$, Moisès Graells $^{2}$ \\ ${ }^{1}$ Chemical and Environmental Engineering Department, Engineering Faculty of Bilbao, University of the \\ Basque Country (UPV/EHU) (Spain) \\ ${ }^{2}$ Chemical Engineering Department, Universitat Politècnica de Catalunya (UPC) (Spain) \\ jesus.requies@ebu.eus, ${ }^{*}$ Corresponding author: ion.agirre@ebu.eus,laura.barrio@ebu.eus,moises.graells@upc.edu
}

Received September 2017

Accepted January 2018

\section{Abstract}

This work presents the assessment of the development and evolution of an active methodology (Project-Based Learning -PBL-) implemented on the course "Unit Operations in Environmental Engineering", within the bachelor's degree in Environmental Engineering, with the purpose of decreasing the dropout rate in this course. After the initial design and implementation of this methodology during the first academic year (12/13), different modifications were adopted in the following ones (13-14, 14-15 \& 15-16) in order to optimize the student's and professor's work load as well as correct some malfunctions observed in the initial design of the PBL. This active methodology seeks to make students the main architects of their own learning processes. Accordingly, they have to identify their learning needs, which is a highly motivating approach both for their curricular development and for attaining the required learning outcomes in this field of knowledge. The results obtained show that working in small teams (cooperative work) enhances each group member's self-learning capabilities. Moreover, academic marks improve when compared to traditional learning methodologies. Nevertheless, the implementation of more active methodologies, such as project-based learning, in small groups has certain specific characteristics. In this case it has been implemented simultaneously in two different groups of 10 students each one. Such small groups are more heterogeneous since the presence of two highly motivated students or not can vary or affect the whole group's attitude and academic results.

Keywords - Active methodologies, Cooperative learning, Project-based learning, Jigsaw puzzle, environmental engineering, Teamwork.

\section{Introduction}

Traditional education has focused on the development of knowledge based on the figure of the lecturer, with students acting as passive agents (Efstratia, 2014; Mas Torelló, 2011). However, the new design of bachelor's degrees in their adaptation to the European Higher Education Area (EHEA) provides new possibilities. This EHEA comes from the Bologna declaration, where it is indicated that successful learning and studying in higher education should involve students in deep learning (Asikainen, 2014). Within the EHEA, the curriculum is based on learning outcomes, and in order to fulfil this purpose, the dedication time of both students and lecturers has been adapted, as defined by the European Credit Transfer and Accumulation System (ECTS). These ECTS credits are distributed across different activities, such as master lectures, laboratory and classroom activities, and seminars, with their overall purpose being to develop a certain number of learning outcomes that students must achieve during their degree courses (Díaz, 2006). Within these new scenarios, the more distinguishing element 
with respect to the previous system is the student's role, whereby the current one is more active, making the individual the main architect of their own learning. The main consequence of this change is that more active methodologies are required for achieving this goal (Lucas-Yagüe, Coca Sanz, González Benito, Cartón López \& García Cubero, 2011). V.M. López developed formative assessment systems to improve learning in order to adapt students to real workload (López-Pastor, 2011). In addition to this, in the higher education of the twenty-first century the most crucial goal is fostering and stimulating the development of lifelong learning skills such as problem solving and critical thinking (Dolmans, Loyens, Marcq \& Gijbels, 2016). Some authors like Dinsmore and Alexander (2012), think that it is necessary the investigation of deep and surface learning to have a critical discussion in any area. However, sometimes this kind of results may be ambiguous and result in inconsistent findings, probably due to the conceptualization of the deep and surface learning and the way in which the concepts are measured. To avoid this type of problems, they propose several actions:

- define clearly, starting from a clear theoretical framework, what deep learning is,

- investigate deep learning within a specific learning context, since the context may influence deep learning, and

- measure deep learning by means of valid tools.

Taking into account these recommendations, it is necessary to make a decision about the employed methodology, since this methodology should convert the students in the main actors of their learning process; it also should provide a critical thinking to a deep learning, and finally, it should measure the student knowledge in the best way possible.

Among the different active methodologies, Project-Based Learning (PBL) is one of the most important ones in the field of engineering. PBL provides students with the responsibility and the opportunity to take part in their own learning process. The core notion of PBL is the focus on real problems that capture students' interest and provoke serious thinking, as students need to acquire and apply new knowledge in an open problem-solving context (Ergül \& Kargin, 2014). The PBL is based on the resolution of an openended project to acquire a deep learning of specific skills in a certain subject. During the PBL, students work in small groups where the open-ended project is discussed before any preparation. This initial brainstorming is used to activate student's prior knowledge since they are not able to fully understand the presented scenario. After the initial brainstorming, the students have an adequate individual self-study period. Afterwards, the students gather again a discussion about the scenario while the professor facilitates the discussion with different driving questions, tips, or tools for a better understanding of the initial scenario and facilitate the acquisition of the required skills in order to solve the problems (Barrows, 1996). This methodology combines the individual self-study and team-work to acquire the skills to solve the project. Thus, the PBL methodology encourages a deep approach to the learning since the students have to discuss in groups relationships among concepts and principles, integrate different literature resources, apply this concepts and principles to the proposed initial scenario/project (Dolmans et al., 2016). The desired aim of this type of methodology is to help the student to build a broad and flexible learning process that may be transferred to other academic or non-academic spheres, develop different skills to solve problems efficiently, self-learning skills, take advantage of cooperative learning, and therefore learn how to work in a team, and be inherently motivated to learn (Hmelo-Silver, 2004). Although autonomous learning is very important, the lecturer's role as a guide is also essential (Barrows, 1996; Cheong, 2008). However, this change in role implies an additional workload. What's more, students may be somewhat reluctant to adopt the new role, since it requires more effort, and it is easier for them to adopt the passive role they would have had with a more traditional learning methodology (Baptiste, 2003). Therefore, the role of the professor is very important in PBL, not also as a guide of the student in the learning process but also as motivating their students to catch the new role.

First experiences on active methodologies were mainly based on problems. For example, the McMaster University Faculty of Health Sciences (Canada)was the first one that established a new medical school 
with an innovative educational approach to be used throughout its entire three-year curriculum, an approach that nowadays is known worldwide as Problem-Based Learning (Barrows, 1996). At about this time, the college of Human Medicine at Michigan State University (USA) implemented a problem-solving course in its preclinical curriculum. This experience was the motivation for new medical schools such as Maastricht (Netherlands), Newcastle (Australia), University of New Mexico (Mexico), University of Hawaii (USA), Harvard (USA), University of Sherbrooke (Canada) and others (Barrows, 1996). As it can be observed, there are a great number of Universities in USA.In the case of the engineering area, this methodology has been applied at McMaster University, Aalborg University (Denmark), and at University of New South of Wales (Australia), among other important universities. One step forward is the PBL in which more realistic scenarios are proposed to the students. Usually this methodology takes several weeks instead of the several days. Moreover, due to the open orientation of the scenario, students must look for more information in the literature and choose their own strategy. However, there are also several similarities: students work in groups, professor's guidance is essential as well as the non-face to face learning.

As it can be observed, all these experiences involve a wide range of different fields of knowledge: engineering, medicine, science, etc. In all of them, the student must develop different strategies in order to pursue a real project. Successfully completing the given project requires students to detect their learning needs and develop their competences on their own accord. There are also some experiences in the engineering area, for instance, Professor Felder (Bullard \& Felder, 2007a, 2007b; Felder, 1996; Felder \& Brent, 1994; Prince \& Felder, 2006; Slavin, 2010) was among the pioneers in the application of this kind of methodology in the Chemical Engineering area. This area, together with Environmental Technologies is the main field of knowledge taught on the course under study in this paper. Based on these experiences, and the formulating PBL characteristic, it was concluded that PBL can also be implemented in environmental engineering courses.

\section{Objectives - Course context}

This work presents the assessment of the development and evolution of an active methodology (ProjectBased Learning -PBL-) implemented on the course "Unit Operations in Environmental Engineering", within the bachelor's degree in Environmental Engineering at the Engineering Faculty of the University of the Basque Country. It corresponds to the fifth semester; it is compulsory, and it has been assigned six ECTS credits distributed in 15 weeks.

This course contains many abstract concepts related to mass transference phenomenon and phase equilibria, and once these concepts are acquired, students have to analyse, understand and design a unit's core operations and the processes to be applied in typical problems of environmental engineering. Table 1 shows a summary of the most important learning outcomes to be acquired. The students consider it as a "tough" course in comparison with other courses of the degree. Thus, historically the dropout rate of the students has been very high (around 30-40\%); they start not attending the lectures and finally they do not take the final exam. From the educational point of view, this issue represents a problem and these dropout rates must be decreased. 


\begin{tabular}{|l|l|}
\hline LO1. & $\begin{array}{l}\text { Know and comply with current legislation when environmental engineering is in any way involved in } \\
\text { the development of different kinds of projects. }\end{array}$ \\
\hline LO1. & $\begin{array}{l}\text { Gain expertise in the analysis, design, simulation and optimization of those processes (natural or } \\
\text { not) with environmental relevance. }\end{array}$ \\
\hline LO2. & $\begin{array}{l}\text { Take part in the design, development and execution of different engineering solutions to } \\
\text { environmental problems, including the evaluation of alternative strategies. }\end{array}$ \\
\hline LO3. & $\begin{array}{l}\text { Know how to use concepts such as mass and energy balances, mass transfer, separation operations, } \\
\text { and the engineering of chemical reactions. }\end{array}$ \\
\hline LO4. & $\begin{array}{l}\text { Make use of different design and management concepts in real operating conditions and in the } \\
\text { simulation of processes involving environmental engineering, heat transmission, fluids, or mass } \\
\text { transfer units. }\end{array}$ \\
\hline LO5. & \begin{tabular}{l} 
Learn to write engineering reports (cross-learning outcome) \\
\hline
\end{tabular}
\end{tabular}

Table 1. Learning outcomes of "Unit Operations in Environmental Engineering" course

In this context, during the 2012/13 academic year, PBL was implemented during the first eight weeks out of a total of 15 weeks (three ECTS credits). In the following three academic courses (2013/14, 2014/15 and 2015/16), based on the experience gained, the PBL was modified/optimized to include a number of minor changes with a view to improving the self-learning process, correcting some malfunctions observed in the initial design of the PBL and optimizing the student's and professor's work load. The main objective of the PBL implementation was to decrease the mentioned dropout rates of this course and improve the learning process by means of a motivation increase using an active methodology.

Hence, this paper explains the development and evolution of the active PBL used in the aforementioned course. Finally, the results recorded both in the implementation and in the evolution of PBL will be discussed.

\section{Methodology and activities}

\subsection{Learning methodologies}

Students had to carry out the project described below. In order to do so successfully and achieve the corresponding learning outcomes, different activities were programmed. Some of these activities had to be carried out in small groups and some of them individually. The group activities prevailed in order to take advantage of teamwork, but individual tasks were also implemented in order to ensure the five elements of cooperative learning: positive interdependence, individual and group accountability, interpersonal and small group skills, face-to-face interaction, and group processing (Walker, 1996). The groups had three members, and they were randomly formed.

The procedure for tackling the project is as follows: first of all, a driving question is submitted to the students, and then a more detailed and realistic scenario is presented to them. Both the driving question and the scenario must be as motivational as possible. This paper reports the experience and evolution of PBL over the last four academic years. However, it should be noted that although the PBL scenario was similar in all the cases, a number of changes were made each year. Thus, during the first two years the students had to deal with the environmental problems that a coal-fired power plant can cause in the atmosphere. They had to study combustion conditions, the production of sulphur-containing gases, and their minimization by means of the design of an appropriate absorption column, which is one of the most important unit operations in environmental engineering. Although the general scenario was quite similar over these two academic years, it was not as open during the second year as in the first one, and it was slightly more delimited. In the third academic year, although the main structure of the PBL was maintained, the driving question and the scenario were changed to avoid information transfer among the students from one year to the next. Thus, the new driving question and the new scenario were related to the possibility of $\mathrm{CO}_{2}$ capture from a combined gas-steam turbine power plant, which is located nearby the Engineering Faculty where this course takes place. Again, the students had to study combustion 
conditions, find out which pollutants are produced, and how $\mathrm{CO}_{2}$ can be captured, designing the corresponding installation. The driving question and the scenario proposed are as follows:

What can the environmental engineers of "Boroa" combined cycle plant do in terms of climate change? You are a group of environmental engineers hired by the "Boroa" plant. Because of the climate change, your boss wants to reduce CO2 emissions, and by the way give a greener image of the plant. In Europe and America, several plants have implemented several CO2 capture systems and your boss wants to follow this path to give a greener image to the company.

He has asked you to develop and design a project to achieve that goal, indicating what processes, equipment would be needed as well as the operating conditions and the dimensions they should have. Your boss, anticipating that there may be major changes in the plant, wants to minimize other types of gaseous emissions and asks you to reanalyze the entire combustion system of the plant.

Once finished the project asks you to give a detailed report of the project and then explain it to bim by means of a poster.

* "Boroa Combined Cycle Power Plant" is located at $20 \mathrm{~km}$ from the engineering faculty where this subject takes place.

The students have to reach to know their learning outcomes. Thus, the steps that they have to analyze are the following ones:

- How a combined cycle power plant works in general and its combustion process in particular.

- All the combustion process by means of material and energy balances and real data obtained directly from the plant.

- Commercially available $\mathrm{CO}_{2}$ capture techniques and decide which of them can be applied in the plant.

- Design the chosen $\mathrm{CO}_{2}$ capture facility (like an absorption column).

In this way, the students will cover different topics like mass and energy balances, mass transference, absorption columns and the design of packed/tray columns by means of a real scenario and working with real data.

Different activities were carried out over eight weeks (duration of the PBL process) in order to develop and achieve the different learning outcomes after presenting the aforementioned scenario:

- Brainstorming: this process generates a plethora of ideas in a short period of time. It is a good tool for generating questions and jointly developing the path to be followed in the PBL process. As a precaution, a few guide questions need to be prepared (which type of fuel uses a combined cycle power plant? Which is its composition? How it works? Which are the main pollutants? ...), especially during the first days when the students tend to be more reserved. This activity is employed after presenting the scenario; students have to leave the classroom with a list of ideas/questions to be answered in order to understand which the structure of the project is.

- Participatory "master classes" or small talks of 15-20 minutes were implemented in the second academic year. They are not true master classes, as their purpose is to provide the students with a small amount of information to help them develop the rest of the information for themselves. This type of activity is used to guide students in some topics that can be broad and quite complex (Smith, Sheppard, Johnson \& Johnson, 2005). One example of this kind of small talks is a brief explanation about mass transfer and mass transfer coefficients. As there are whole books incorporating mass transfer concepts and developing complex equations, our experience is that students get lost without a short explanation in order to guide them. 
- Jigsaw puzzle: each team member or each team (depending on the jigsaw puzzle) takes responsibility for one aspect of the problem, and then all the information is shared with the other team members or with the other groups. Expert teams were also formed among those students responsible for the same aspect.

- Pooling of results: after working on a certain activity (usually after Jigsaw puzzles), each student group shares its conclusions, prompting a discussion among them. The aim was to promote analytical, evaluative and creative thinking.

- Tasks-solving in groups: the great advantage of solving tasks in groups lies in the use of synergies. Thus, students move forward more efficiently in their learning process. Along the PBL, apart from the main report that gives a solution to the initial scenario or project, the students have different deliverables related to the different concepts that have to be developed and appeared in the initial brainstorming process.

- Computing labs: a chemical process simulator was used in order to calculate the required thermodynamic properties in PBL (only during 2012-13 \& 2013-14).

- Oral presentations: students have to carry out two oral presentations along the 8 weeks of the PBL. The professor appoints, at the time of presenting, which team member starts presenting, finishes... this action is related to the individual accountability; all team members must know every point of their work.

- Poster: once the project had finished, students had to write a report and make an oral presentation with a poster. The use of a poster requires students to summarize the project by selecting only the most relevant information.

- Tutorials: both individual and in groups.

As it has been previously mentioned, sundry other activities were implemented in the 2014-2015 academic year with the purpose of correct some malfunctions observed in the initial design of the PBL and improve the self-learning process by means of an increase of the motivation. In some deliverables, we noticed that students felt a bit disoriented due to the difficulty and amount of the concepts/information that they had to develop. Thus, before asking for deliverables more classroom activities were designed (three more Jigsaw puzzles were implemented) in order to take in the concepts little by little. Moreover, hardly individual assignments were designed and it was not possible to ensure the individual accountability so two "minimum knowledge tests" were included during the PBL. These tests measure the acquisition of basic knowledge of each student and they have to pass them if they want to pass/keep on the PBL. Moreover, in order to increase their motivation and be in contact with more real processes a visit to a gassteam turbine power plant (directly related to the presented scenario) and lab experiments working with lab scale pilot plants were also included. In 2015-2016 academic course some additional changes were performed in order to optimize the student's and professor's workloads; peer-to peer evaluations were included in order to decrease professor's work amount and the assignment of two deliverables were reduced. These changes are described in the following paragraphs:

- Visit to "Boroa" gas-steam turbine power plant: Prior to the visit, the students have to understand how the combustion takes place and they have to guess which data are required in order to check the combustion process. After the visit to the gas-steam turbine power plant, the basic scenario is settled and the visit can provide to the students with an additional source of information. The students thoroughly enjoy the visit, as it was closely linked to the PBL process. They had a chance to ask numerous questions, get real data to face their assignment and gain a better understanding of the real performance of a gas-steam turbine power plant. 
- Peer-to-Peer evaluation: after solving problems in groups, peer-to-peer evaluations were proposed. The aim of this activity was to develop the students' analytical and evaluative skills. Moreover, this kind of activities helps to balance the professor's work load.

- Lab experiments: $\mathrm{CO}_{2}$ absorption lab experiments were carried out using a lab-scale pilot plant. These experiments help students to understand the operation of an absorption column much more clearly.

- Minimum knowledge tests: two different individual tests were held during the PBL, with the aim being to ensure that all the team members develop the required minimum skills during the learning process.

A large workload was included when each of these activities were designed. One of the reasons of designing such a workload is to avoid the possibility of performing all the work by only one team member. A positive interdependence wants to be ensured in the way that all team members need to use the information that other team colleagues have. Moreover, classroom hours were also used to develop the activities, thus, students have to work together, face to face, learning from their mates and sharing their knowledge (Prieto, 2007). However, some activities like the "minimum knowledge tests" or the oral presentations, that have to be done in a random order decided by the professor, are also included in order to ensure the individual accountability and avoid the presence of team members that do not do anything.

Jigsaw puzzles are one example to perform cooperative learning skills taking into account all the previously mentioned considerations. This technique structures the work in teams but with the mentioned positive interdependence. This activity was utilized 3 times along this PBL design. In the following steps one of them is explained:

1. The professor wants to develop thermochemistry to be applied afterwards in combustion systems. For that purpose, this topic was divided in three documents where the starting point is an everyday situation in order to motivate them.

- Saturation point, phase change, effect of pressure and temperature:

- The students have to understand why pasta is cooked in 10 minutes but it takes longer if it were cooked on top of the Everest Mountain.

- The students have to understand why cooking in a normal pot takes longer than in an express pot.

These are only easy examples that only take a few time and allow to link everyday situations with thermochemical concepts included in the Academic Plan.

- Once these situations are understood, the students have to solve one exercise related to the saturation point and phase change.

- Enthalpy of reaction and formation enthalpies:

- When I burn wood some gases and heat is released. Why? Students have to investigate why in some cases heat is released from a chemical system and some other times heat must be added to them. They have to discover what the "enthalpy of reaction" is and how it can be calculated.

- Once they understand it they have to solve an exercise in order to calculate the enthalpy of reaction of a certain reaction at a certain temperature. 
- Heating value, adiabatic flame temperature.

- What is the "heating value" that appears in the Natural Gas invoice that we receive every month at home? What does it mean?

- Once they understand this concept they have to apply it in a certain exercise.

2. Students are divided in groups of three and each member will be assigned with one of the previous tasks that have to develop in his/her own. All the students with the same number (see Figure 1) have to develop the same task.

3. Once the estimated time for the previous step is gone, all the students with the same numbers will meet together in the so-called "Experts' meeting". They will share all the information, check if all reached to the same conclusion and finally they will try to see which the best way is to transmit this information to the rest of the team mates

4. In the 3rdstep, the original teams meet back and each team member explains his/her part to the whole team. They have to realize that the first to task are connected since when calculating a certain enthalpy of reaction phase changes are also involved. Besides, the 2nd and the 3rd tasks are also connected since the heating value is one way to give a certain enthalpy of reaction (for combustion processes).

5. Finally, each team has to evaluate what they learned and has to apply all these concepts solving a simple energy balance of a simple industrial process. Afterwards, they have to apply all these concepts when trying to give a solution to the proposed initial scenario.

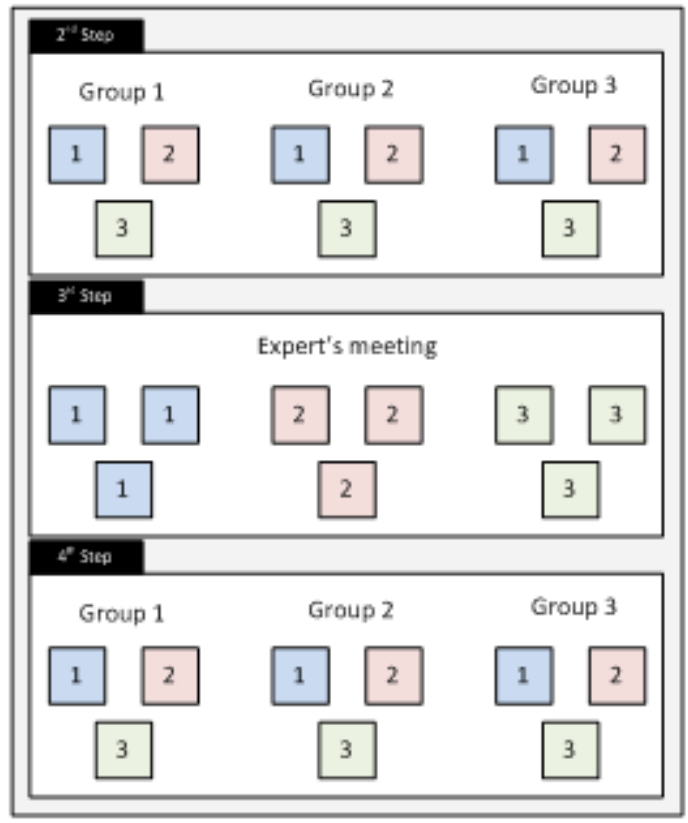

Figure 1. Main steps of Jigsaw Puzzle activity

Besides all these activities, other tasks were used to control the normal functioning of the teams and identify any possible team dysfunctionalities. The students did two different tests in the middle and at the end of the PBL. The purpose of these two tests was to check each team's performance. In the first test, each team had to evaluate (answer some questions) their behaviour as a team (self-assessment). In the other test, each member of the team had to evaluate their peers individually, as well as themselves, by means of a questionnaire (self- and co-assessment). 
Figure 2 shows the existing relationship among all the deliverables and activities. On the one hand, there are three types of deliverables:

- Those that are not evaluated and are related to the control of each team's normal functioning, and identify possible team dysfunctionalities.

- Those related to the development and fleshing out of concepts.

- Those related to the solution of the initial scenario considered.

On the other hand, all the activities described above are carried out just before the deliverables, as most of these activities are designed to develop concepts.

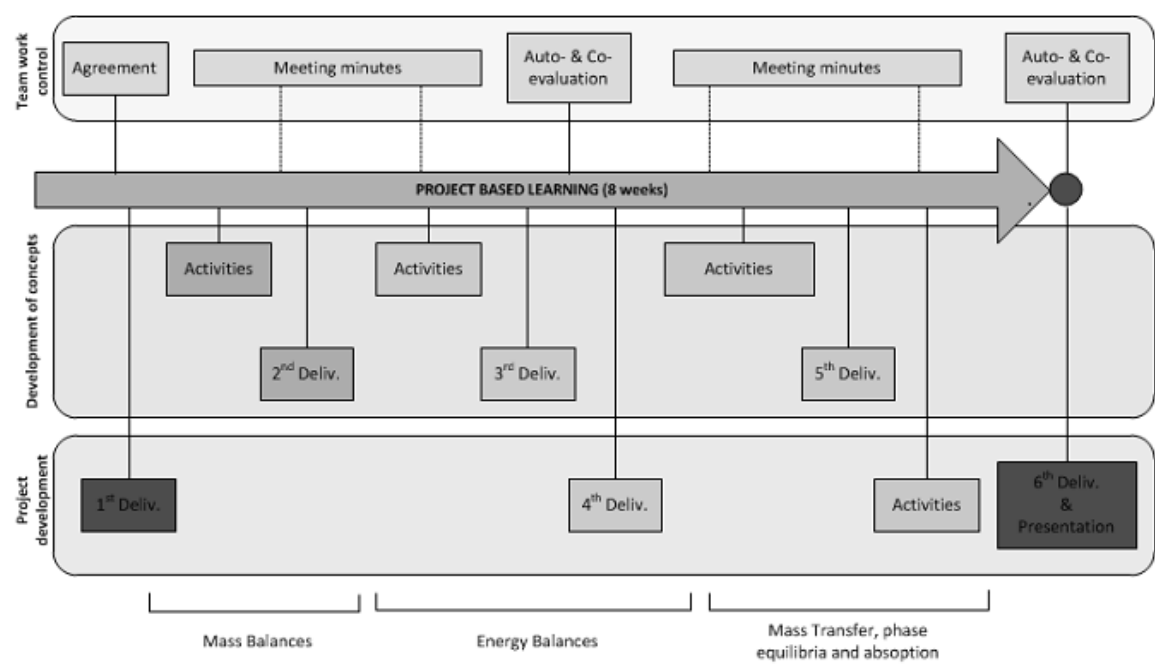

Figure 2. Relationship between the activities and different deliverables

\subsection{Information sources and other resources}

The use of new information and communication technologies (ICTs) has had a major influence on the development of PBL, as they reduce time and space limitations. Students can save time and better organize their presence, or not, at the university's facilities, as they can use the university's resources to look up information remotely via a VPN connection. Furthermore, the use of "Learning Content Management Systems" allows lecturers to supervise work, as well as share information with the students. In this case, a Moodle version customised by the University of the Basque Country (eGela) was used.

The students' main information sources were books and eBooks from the faculty library, certain websites (only recognized or well-known websites were recommended), scientific research articles, data sheets prepared by the lecturer, and the aforementioned visit to the power plant.

\section{Evaluation}

The evaluation of both the project and the course have changed over the course of the four years under study. Therefore, this section describes and explains the differences.

\section{Academic year 2012/13}

The overall course assessment was as follows:

- A final exam: $60 \%$ of the total mark

- PBL methodology: $35 \%$ of the total mark 
- Computing lab: 5\% of the total mark. Aspen Plus usage was evaluated

An individual exam was held at the end of the course; the learning outcomes achieved both in the PBL project and with the traditional methodology (second semester) were evaluated. Hence, the students should have developed the required competencies and gained a minimum knowledge that had to be proven in the final exam. Passing the exam was a compulsory requirement for successfully completing the year. This exam involved the design of different operating units, and certain questions had to be discussed.

In the case of the PBL project, students were evaluated according to different deliverables. In 2012/13, seven deliverables were addressed, all of which were compulsory, but three of them were not evaluated.

1. Founding charter. This deliverable is related to the formation of the groups. Each group was formed by three students, and they had to sign an agreement in which they had to set their own rules, responsibilities, and each team member's role. This deliverable was not evaluated.

2. Analysis of project needs. After a brainstorming process, students had to identify the environmental problems derived from fossil-fuel combustion and possible solutions for reducing SO2 emissions. This deliverable was not evaluated.

3. Flow chart of the proposed scenario $(10 \%)$.Students had to draw up a flow chat of their process, and select a coal, indicating its elemental and proximate composition. In addition, they had to estimate its Higher Heating Value.

4. The proposed scenario's mass/energy balances and pertinent environmental regulations. In this case, and according to the megawatt rating, students had to calculate the required amount of coal and calculate the mass balance of the combustion process, indicating the outlet gas composition. In addition, students had to check the corresponding emission limits (legislation) in order to find out how much $\mathrm{SO}_{2}$ had to be removed.

5. Mass-transfer. In this case, after brainstorming mass-transfer processes, students individually had to answer several questions related to chemical equilibrium, Fick's Laws, diffusivity or diffusion coefficients, global and individual mass-transfer coefficients, etc. This deliverable was not evaluated.

6. Jigsaw puzzles $(25 \%)$. Students worked on three different tasks, with one of them being assigned to each member of the group. Those students responsible for the same task formed a new group, and prepared their task in depth. Thus, a member of each group became an expert in one of the tasks. After preparing the tasks, each team member returned to their original group, and they pooled all the information.

7. Poster (50\%). Taking into account all the calculations performed in the previous deliverables (mass and energy balances, the mass-transfer phenomenon, chemical equilibrium, the use of tray towers or packing towers, the design of scrubbers...), students had to defend their project in front of their peers and two lecturers: the one in charge of the course and an additional guest lecturer with expertise in the field.

\section{Academic year 2013/14}

The overall assessment percentages for passing the course were maintained in 2013-2014. The main difference involved the number of deliverables. In this case, there were fewer deliverables (numbers 2 and 5 were removed), and the scenario was changed slightly. The main goal was also to burn coal in a typical coal-fired thermal power plant, with the design of a fixed number of scrubbers. However, on this occasion the megawatts and other parameters, such as air feed and the production of $\mathrm{SO}_{3}, \mathrm{NO}$ and $\mathrm{N}_{2} \mathrm{O}$, were pre-set. The project was not therefore as open as in the previous year. This year, the learning outcomes related to the mass transfer were covered by participatory master lectures. As this topic is very 
extensive, and learning from the experience of the previous year, it was decided to instruct students through participatory "master classes".

\section{Academic years 2014/15 and 2015/16}

The assessment percentages were tweaked slightly:

- PBL methodology: $45 \%$ of the total mark

- A final exam that covered only those concepts that were not evaluated in the PBL (i.e., the concepts studied during the second semester according to a traditional methodology)

- Lab experiments: $10 \%$ of the total mark.

In this case, the exam covers only the syllabus of the second part of the course, which is based on a traditional methodology, and its weight therefore decreases in the total mark for the year. In addition, the weight of the PBL increases to $45 \%$, and as mentioned above, two separate minimum knowledge tests were incorporated into the year.

The deliverables evaluated in this case were as follows:

1. Analysis of the scenario presented (5\%): students analyse the scenario and describe the project's different possible stages or steps. Moreover, the students are required to describe the key concepts of a Combined Cycle Power Plant, and check regulatory atmospheric emission levels (legislation).

2. Problem-solving in groups - Mass balances (5\%): after working on different concepts related to mass balances, each group of students had to solve a given mass balance problem.

3. Problems-solving in groups - Energy balances (10\%): after working on different concepts related to energy balances, each group of students had to solve a given mass and energy balance problem.

4. Study of the combustion process in a Combined Cycle Power Plant (35\%): students had to build the mass and energy balances applicable to a specific power plant near the university. The students had the opportunity to visit this power plant and ask the necessary questions to gather missing data for their calculations.

5. Problem-solving in groups - Absorption towers (10\%): after studying mass-transfer phenomena and solving a jigsaw puzzle with three different elements (packing towers, tray towers, and adsorption processes), students are required to design a specific adsorption tower in groups.

6. Final report and presentation (25\%): students report on the project's development, addressing all combustion mass and energy balances, as well as the design of the solution they found for the $\mathrm{CO}_{2}$ capture process. Moreover, they had to prepare a small poster to summarize the relevant information in order to present the project to their peers, the lecturer and an additional guest lecturer with expertise in the field.

The final $10 \%$ of the overall mark for PBL corresponds to the two minimum knowledge tests. 


\section{Results and discussion}

\subsection{Academic results from the lecturer's perspective}

Overall, the feedback obtained over the four years was quite positive in terms of the working atmosphere, the quality of the work, and the learning outcomes achieved. Most of the pre-set activities turned out satisfactorily, and they all fulfilled their purpose. The dialogue between lecturer and students was very fluid. This made it easy to guide the students in the right direction. Teamwork was also satisfactory, and no dysfunctionalities were detected among the members of each team. In the middle and at the end of the PBL, self and co-assessment questionnaires were filled out by the students (see Figure 2), and no problems were detected within the teams.

One very positive aspect of implementing PBL is that students learn to make decisions. They are used to solving specific closed problems, while in PBL, they have to set their own goals, and they have to fix some parameters and calculate others... Thus, they made use of the recommended bibliography, and the visit to the power plant company was very useful, as they had already studied the process and were able to make intelligent questions in order to gather the data they needed.

One difference in 2014-2015 was that the PBL methodology was implemented in two different groups (G1 and G2), each one having 10 members (only one group of 12 students in 2012-2013, 2013-2014 and 2015-2016). Both groups correspond to the same course, degree and period of time; the only difference was the language used, Basque in one case and Spanish in the other. The same activities and the same deliverables were involved in both groups, but the results obtained were different in both cases. In one of the cases (G1), the students were much more active, with the brainstorming processes and the classroom discussions being much more rewarding. Therefore, an important conclusion is that the success of the proposed activities depends on the type of students.

In general, it may be stated that students keep abreast of their work during the PBL process, which helps when carrying out different activities in the classroom. By contrast, during the second half of the course, when a traditional teaching process was followed, it was observed that the students did not keep up with the work, and this difference in their attitude was reflected in the final marks. Figure 3, Figure 4, Figure 5 and Figure 6 show that the marks for PBL were much better than the marks obtained for the whole year. (A represents a success rate of between 90 and 100\%, B between 70 and $90 \%$, C between 50 and $70 \%$, and $\mathrm{D}$ below $50 \%$ ). Nobody failed (D) the PBL course in any of the academic years, but there are several fail grades overall, which means that knowledge acquisition using a traditional methodology was not as satisfactory as during PBL. 


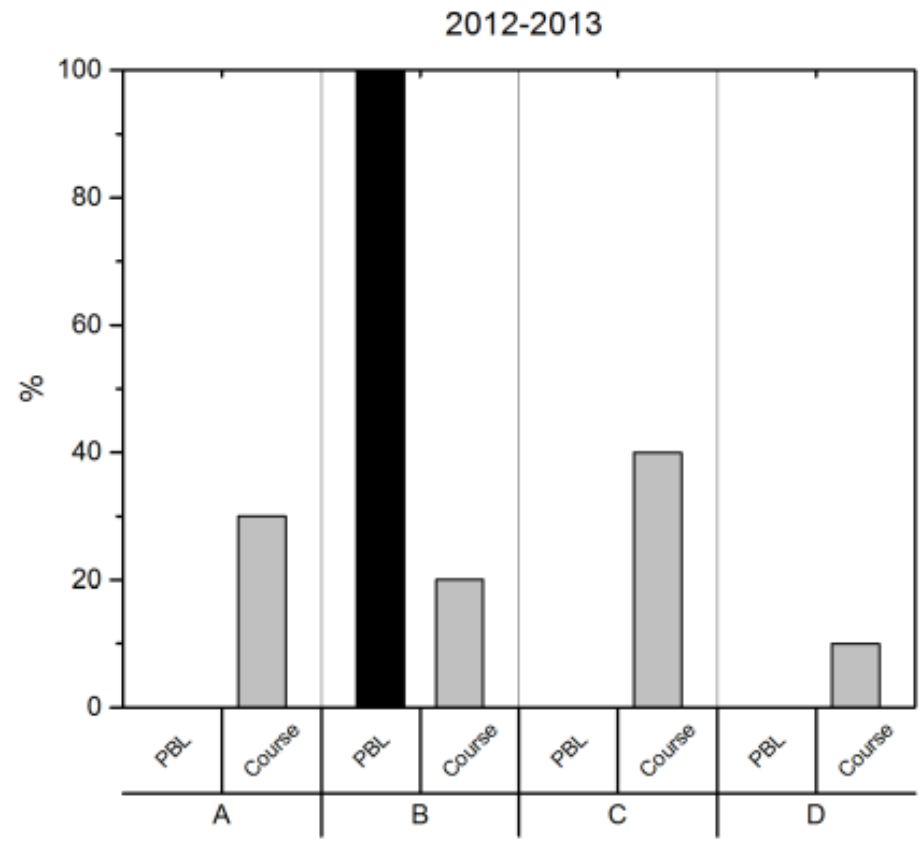

Figure 3. Marks for PBL and the whole course in 2012-2013

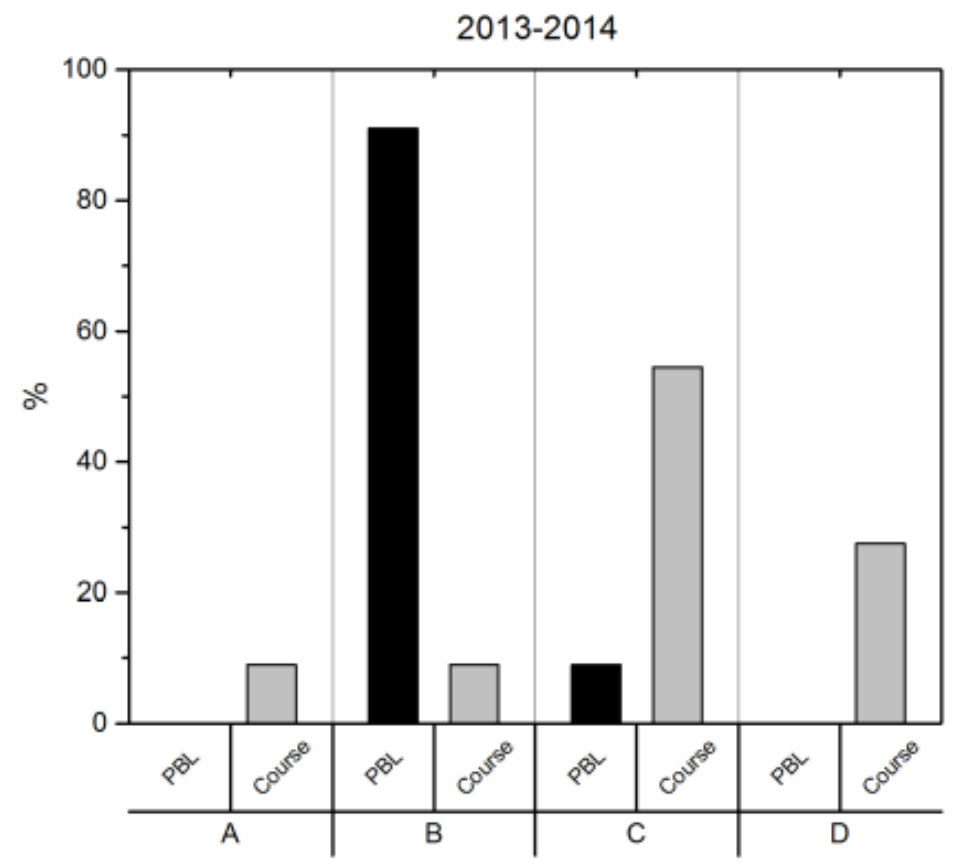

Figure 4. Marks for PBL and the whole course in 2013-2014 


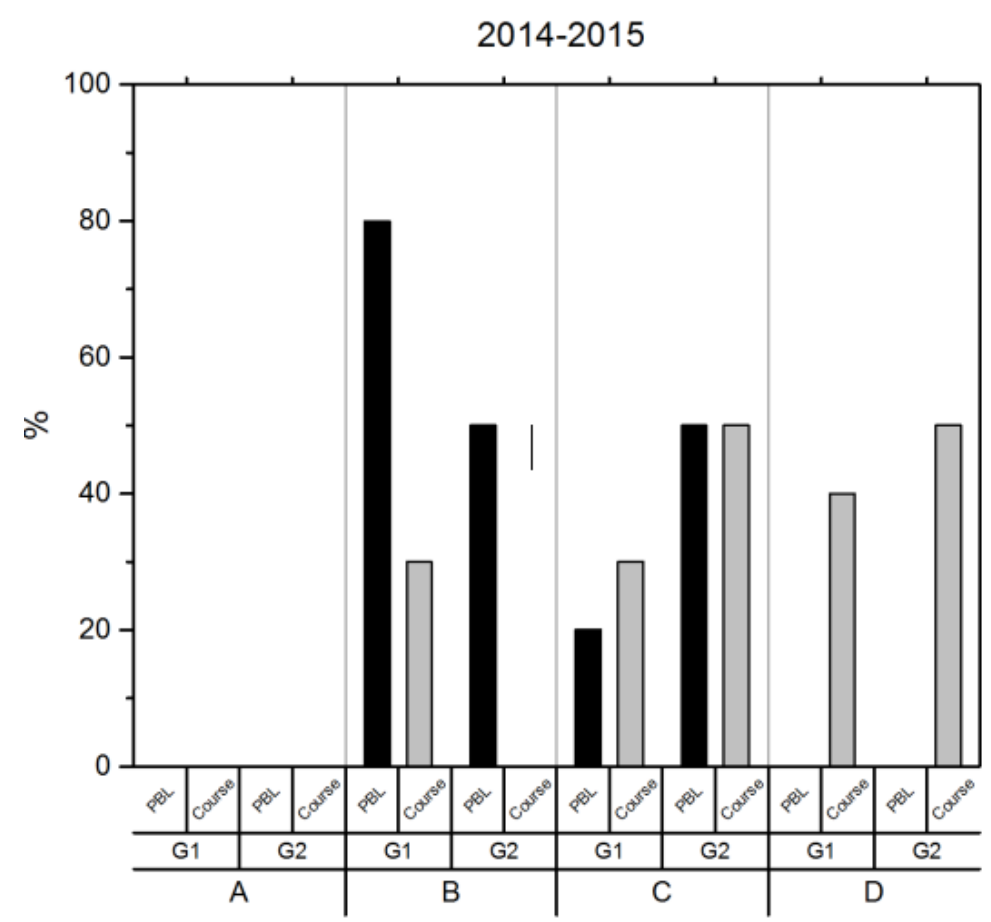

Figure 5. Marks for PBL and the whole course in 2014-2015

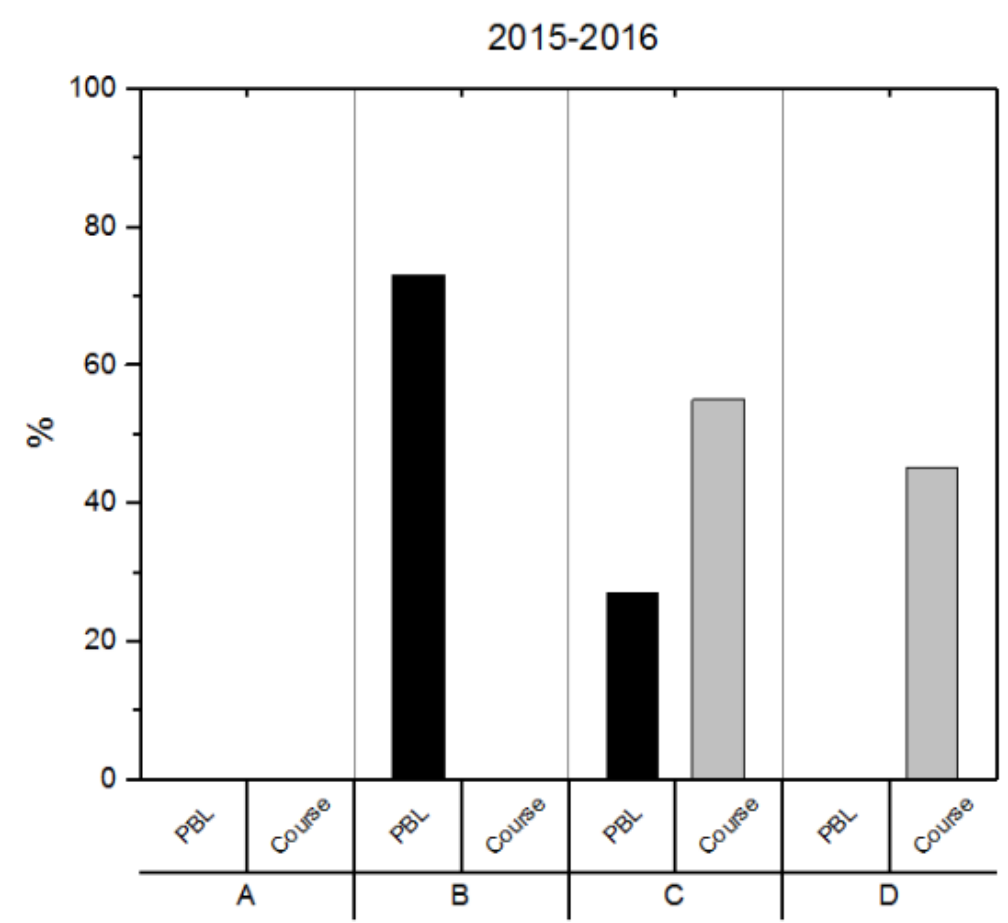

Figure 6. Marks for PBL and the whole course in 2015-2016

\subsection{Student feedback on PBL}

After finishing the PBL, the students filled in an anonymous questionnaire to analyse their learning process during the course, their motivation, their opinion about the different activities involved in PBL, and the main problems or drawbacks they had encountered. A brief summary of the questionnaire's 
results is provided in Table 2a. This information is essential for helping lecturers to improve the PBL course and increase student motivation, with the specific aim of enhancing their learning process.

The increase in student motivation with respect to the traditional methodology is confirmed; however, there is no correlation between student motivation and academic results. The best results in terms of motivation were recorded in the last three academic years, yet the corresponding academic results were worse than in 2012/13.Although this statement seems to be in disagreement with published literature ("Less Talk, More Action: Improving Science Learning," 2011), it must be taken into account in 2012/2013 academic year, this methodology was completely new for both, students and professor, and probably the real motivation rate of students and the evaluation tools employed had room for improvement. This fact can also be supported with the data in which only $42 \%$ of the students would continue or choose again the PBL methodology if they could select it for other courses(data achieved from the students' survey). Moreover, Dinsmore and Alexander (2012) and Gibbs and Simpson (2004) discuss how the usage of evaluating valid tools is essential to get appropriate learning measurements.

In addition, leaving aside this first year, the students in the last three years felt they learned more than with the traditional methodology. The project's assessment was very good for these students, and they would like to continue with this type of methodology in the future. However, some students think that the use of this type of active methodology is conditioned by the nature of the subject. In $2013 / 14,89 \%$ of the students said they would like to continue with this type of methodology, while in 2014/15 there was a drop to $60 \%$. On the one hand, this drop could be related to the higher motivation rate among students in 2013/14, but on the other hand, it should be noted that several students in 2014/15 found the methodology very positive, but they would not continue with it due to the high workload it involved. Moreover, it must be remarked that, as it is previously explained, in 2014-2015 academic year some more activities were implemented which led them to a higher work amount both for students and for the professor. For this reason, the later design had to be slightly adapted in 2015-2016 academic year, reducing the assignments of some deliverables and introducing peer to peer evaluations in order to reduce both student's and professor's work load. In 2015/16 the percentage of students that would continue with the PBL raised to $83 \%$ being the main reason of those students that would not continue with the PBL the high workload, although they think that they learn more efficiently. Therefore, it can be concluded that the PBL design was better than the previous ones in the last academic year. The presence of two highly motivated students or not may affect considerably the results of the questionnaires but overall, it may be stated that the feedback is positive. The problem of the student workload, or at least their subjective assessment, seems to be a common problem in general in the ECTS studies (López-Pastor, 2011).

Finally, as mentioned above in "Academic results from the lecturer's perspective", in the 2014/15 academic course the same project was applied to two different groups of 10 members each one. It has already been discussed that the academic results were quite different between the groups; however, the results for motivation, self-learning, project evaluation, and the other parameters were fairly similar in both groups.

In general, students prefer active methodologies to the traditional approach, but the main criticism is the amount of time they need to dedicate to preparing PBL, and the fact that they are evaluated both during the PBL process and in the final exam. In response to these grouses, in the last two academic courses the project's learning outcomes were not evaluated in the final exam. This change seems to improve the project's appraisal by the students, as the number of very highly satisfied students peaked in the final year studied.

Therefore, although there are certain reservations about the active methodology used throughout the course, it may be stated that the students' overall opinion is positive. Motivation is higher than with the traditional approach, and teamwork enhanced the relationship among students, and the dialogue between students and lecturer is also more fluid, with all these factors leading to a constructive working atmosphere in which the students oversee their own learning process. 


\begin{tabular}{|c|c|c|c|c|c|c|c|c|c|c|c|c|c|c|c|}
\hline \multirow{3}{*}{\begin{tabular}{|l|} 
Academic \\
year
\end{tabular}} & \multicolumn{5}{|c|}{ Project rating } & \multicolumn{5}{|c|}{ Increase in motivation } & \multicolumn{5}{|c|}{ Development of self-learning } \\
\hline & \multirow{2}{*}{$12 / 13$} & \multirow{2}{*}{$13 / 14$} & \multicolumn{2}{|c|}{$14 / 15$} & \multirow{2}{*}{$15 / 16$} & \multirow{2}{*}{$12 / 13$} & \multirow{2}{*}{$13 / 14$} & \multicolumn{2}{|c|}{$14 / 15$} & \multirow{2}{*}{$15 / 16$} & \multirow{2}{*}{$12 / 13$} & \multirow{2}{*}{$13 / 14$} & \multicolumn{2}{|c|}{$14 / 15$} & \multirow{2}{*}{$15 / 16$} \\
\hline & & & G1 & G2 & & & & G1 & G2 & & & & G1 & G2 & \\
\hline $\begin{array}{l}\text { Not } \\
\text { satisfactory }\end{array}$ & $0 \%$ & $0 \%$ & $0 \%$ & $0 \%$ & $0 \%$ & $25 \%$ & $0 \%$ & $0 \%$ & $10 \%$ & $0 \%$ & $0 \%$ & $0 \%$ & $0 \%$ & $0 \%$ & $0 \%$ \\
\hline Satisfactory & $50 \%$ & & $12 \%$ & $30 \%$ & $8 \%$ & $25 \%$ & $17 \%$ & $37 \%$ & $30 \%$ & $0 \%$ & $0 \%$ & $0 \%$ & $25 \%$ & $10 \%$ & $0 \%$ \\
\hline $\begin{array}{l}\text { Highly } \\
\text { satisfactory }\end{array}$ & $50 \%$ & $84 \%$ & $63 \%$ & $50 \%$ & $50 \%$ & $50 \%$ & $75 \%$ & $38 \%$ & $50 \%$ & $50 \%$ & $100 \%$ & $100 \%$ & $63 \%$ & $40 \%$ & $83 \%$ \\
\hline $\begin{array}{l}\text { Very highly } \\
\text { satisfactory }\end{array}$ & $0 \%$ & $8 \%$ & $25 \%$ & $20 \%$ & $42 \%$ & $0 \%$ & $8 \%$ & $25 \%$ & $10 \%$ & $50 \%$ & $0 \%$ & $0 \%$ & $12 \%$ & $50 \%$ & $17 \%$ \\
\hline
\end{tabular}

Table 2a. Results of student feedback on PBL

\begin{tabular}{|c|c|c|c|c|c|}
\hline & \multicolumn{5}{|c|}{ Would you like to continue with this methodology next year? } \\
\hline & \multirow{2}{*}{$12 / 13$} & \multirow{2}{*}{$13 / 14$} & \multicolumn{2}{|c|}{$14 / 15$} & \multirow{2}{*}{$15 / 16$} \\
\hline & & & G1 & G2 & \\
\hline Yes & $42 \%$ & $89 \%$ & $57 \%$ & $60 \%$ & $83 \%$ \\
\hline No & $58 \%$ & $11 \%$ & $43 \%$ & $40 \%$ & $17 \%$ \\
\hline
\end{tabular}

Table $2 \mathrm{~b}$. Results of student feedback, whether they would continue, or not, with this methodology in the following years

\section{Conclusions}

One of the main conclusion to be drawn from the experience of the PBL process over four consecutive academic years is that the dropout rate has decreased to $0 \%$ in all the years under study, e.g., all the students attended the on-site lectures, worked on the project, felt more motivated and therefore they did not left the course. Some more specific conclusions from the learning process are as follows:

- The success of a given PBL project is subject to students' attitude and aptitude, as confirmed in 2014-2015.

- The use of "participatory master classes" or small talks of 15-20 minutes was positive for guiding the students in complex and broad topics, such as mass transfer. Thus, students were more highly motivated, avoiding moments of frustration when they became stuck and did not know how to proceed.

- The use of PBL led to the achievement of the course's specific learning outcomes, as well as those related to making oral presentations, writing reports, and working in groups.

- The motivation with this type of active methodology is higher than with traditional ones; teamwork enhanced the relationship between students, the dialogue between students and lecturer is also more fluid, and all these factors lead to a constructive working atmosphere in which the students oversee their own learning process.

- The groups are more heterogeneous when they are small, as in the present case (10 students per group). In such small groups the presence of two very motivated students or not can vary or affect the attitude of the whole group. Moreover, the questionnaires' results may differ considerably when the opinion of two students is very positive or very negative, since they represent $20 \%$ of the group.

From the lecturer's point of view, it was checked that the first PBL design was not the optimum one from both the design of deliverables and the evaluating phase. Thus, these aspects were modified along the academic years under study in this paper, and better results were obtained due to the improvements incorporated. The non-correct selection of the evaluation tools in the first year led to incorrect conclusions. Therefore, it can also be concluded that the training of the lecturer is essential. 


\section{Declaration of Conflicting Interests}

The authors declared no potential conflicts of interest with respect to the research, authorship, and/or publication of this article.

\section{Funding}

The authors gratefully acknowledge the financial support for this work provided by the "Quality and Innovative Teaching Vice-chancellorship of the University of the Basque Country (UPV/EHU)" through the project entitled "PBL implementation in several courses in the field of knowledge of Chemical Engineering within Environmental Engineering and Industrial Technology Engineering degrees".

\section{References}

Asikainen, H. (2014). Successful learning and studying in Biosciences: Exploring how students conceptions of learning, approaches to learning, motivation and their experiences of the teaching-learning environment are related to study success. University of Helsinki.

Baptiste, S. (2003). Problem-Based Learning: A Self-Directed Journey (1st Ed.). Thorofase, New Jersey: Slack Incorporated.

Barrows, H.S. (1996). Problem-based learning in medicine and beyond: A brief overview. Bringing ProblemBased Learning to Higher Education: Theory and Practice, 1996(68), 3-12. Wiley. https://doi.org/10.1002/tl.37219966804

Bullard, L.G., \& Felder, R.M. (2007a). A student-centered approach to teaching material and energy balances 1. Course design. Chemical Engineering Education, 41(2), 93-100.

Bullard, L.G., \& Felder, R.M. (2007b). A student-centered approach to teaching material and energy balances 2. Course delivery and assessment. Chemical Engineering Education, 41(3), 167-176.

Cheong, F. (2008). Using a Problem-Based Learning Approach to Teach an Intelligent Systems Course. Journal of Information Technology Education, 7, 47-60. https://doi.org/10.28945/178

Díaz, M. de M. (2006). Metodologías de enseñanza y aprendizaje para el desarrollo de competencias: orientaciones para el profesorado universitario ante el Espacio Europeo. Madrid: Alianza editirial. Retrieved from: http://academicos.iems.edu.mx/cired/docs/tg/macroacademiaquimica/Compendio de libros sobre competencias.doc

Dinsmore, D.L., \& Alexander, P.A. (2012). A Critical Discussion of Deep and Surface Processing: What It Means, How It Is Measured, the Role of Context, and Model Specification. Educational Psychology Review, 24(4), 499-567. https://doi.org/10.1007/s10648-012-9198-7

Dolmans, D.H.J.M., Loyens, S.M.M., Marcq, H., \& Gijbels, D. (2016). Deep and surface learning in problem-based learning: a review of the literature. Advances in Health Sciences Education, 21(5), 1087-1112. Springer Netherlands. https://doi.org/10.1007/s10459-015-9645-6

Efstratia, D. (2014). Experiential Education through Project Based Learning. Procedia - Social and Behavioral Sciences, 152, 1256-1260. Retrieved March 17, 2015, from:

http://www.sciencedirect.com/science/article/pii/S1877042814054299

https://doi.org/10.1016/j.sbspro.2014.09.362

Ergül, N.R., \& Kargin, E.K. (2014). The Effect of Project based Learning on Students' Science Success. Procedia - Social and Behavioral Sciences, 136, 537-541. Retrieved May 19, 2015, from:

http://www.sciencedirect.com/science/article/pii/S187704281403852X https://doi.org/10.1016/j.sbspro.2014.05.371

Felder, R.M. (1996). Active-Inductive-Cooperative Learning: An Instructional Model for Chemistry?. Journal of Chemical Education, 73(9), 832. https://doi.org/10.1021/ed073p832

Felder, R.M., \& Brent, R. (1994). Cooperative Learning in Technical Courses: Procedures, Pitfalls and Payoffs. Reproduction (Vol. 377038). Retrieved June 1, 2015, from:

http://www4.ncsu.edu/unity/lockers/users/f/felder/public/Papers/Coopreport.html 
Gibbs, G., \& Simpson, C. (2004). Conditions under which assessment supports students' learning Learning and Teaching in Higher Education. Learning and Teaching in Higher Education, 1(1), 3-31.

Hmelo-Silver, C. (2004). Problem-based learning: What and how do students learn?. Educational Psychology Review, 16(3), 235-266. https://doi.org/10.1023/B:EDPR.0000034022.16470.f3

Less Talk, More Action: Improving Science Learning. (2011, May 12). The New York Times.

López-Pastor, V.M. (2011). Best Practices in Academic Assessment in Higher Education. Journal of Technology and Science Education, 1(2), 25-39. Retrieved from: http://www.jotse.org/index.php/jotse/article/view/20

Lucas-Yagüe, S., Coca Sanz, M., González Benito, G., Cartón López, A., \& García Cubero, M. (2011). Design and Analysis of Questionnaires for Survey Skills in Chemical Engineering. Journal of Technology and Science Education, 1(2), 40-48. Retrieved from: http://www.jotse.org/index.php/jotse/article/view/25

Mas Torelló, Ó. (2011). El profesor universitario: sus competencias y formación. Revista de currículum y formación del profesorado, 3(Diciembre), 195-211.

Prieto, L. (2007). El aprendizaje cooperativo. Madrid: PPC.

Prince, M.J., \& Felder, R.M. (2006). Inductive Teaching and Learning Methods: Definitions, Comparisons, and Research Bases. Journal of Engineering Education, 95(2), 123-138. Washington: Blackwell Publishing Ltd. https://doi.org/10.1002/j.2168-9830.2006.tb00884.x

Slavin, R.E. (2010). Cooperative Learning. International Encyclopedia of Education (pp. 177-183). CITY: ACS Symposium Series. Retrieved from: http://www.sciencedirect.com/science/article/pii/B9780080448947004942 https://doi.org/10.1016/B978-0-08-044894-7.00494-2

Smith, K.A., Sheppard, S.D., Johnson, D.W., \& Johnson, R.T. (2005). Pedagogies of Engagement: Classroom-Based Practices. Journal of Engineering Education, 94(1), 87-101. Blackwell Publishing Ltd. https://doi.org/10.1002/j.2168-9830.2005.tb00831.x

Walker, A.J. (1996). Cooperative learning in the college classroom. Family Relations (Vol. 45). Edina, MN: Interaction Book Company. Retrieved from: http://www.scopus.com/inward/record.url?eid=2-s2.0$\underline{0030176812 \& \text { partnerID }=40 \& m d 5=117130 a a 10 c 5 a 3 c 822 f 7 c d 0 f 9 b 45 b 7 c 5}$ https: / $/$ oi.org $/ 10.2307 / 585505$

Published by OmniaScience (www.omniascience.com)

Journal of Technology and Science Education, 2018 (www.jotse.org)



Article's contents are provided on an Attribution-Non Commercial 4.0 Creative commons International License. Readers are allowed to copy, distribute and communicate article's contents, provided the author's and JOTSE journal's names are included. It must not be used for commercial purposes. To see the complete licence contents, please visit https://creativecommons.org/licenses/by-nc/4.0/. 